\title{
Correction to: Evaluation of Prostate Needle Biopsies
}

\author{
Giovanna A. Giannico and Omar Hameed
}

\section{Correction to:}

Chapter 4 in: H. Schatten (ed.), Molecular \& Diagnostic Imaging in Prostate Cancer, Advances in Experimental Medicine and Biology 1126, https://doi.org/10.1007/978-3-319-99286-0_4

Author affiliations in chapter 4 was incorrect and it has now been corrected in this version.

Giovanna A. Giannico, MD

Department of Pathology

Microbiology and Immunology

Vanderbilt University Medical Center

Nashville, TN, USA

Omar Hameed, MD

Pathology Medical Director

HCA Midwest Division

Kansas City, MO, USA

Adjunct Professor of Pathology

Microbiology and Immunology

Vanderbilt University Medical Center

Nashville, TN, USA 